$\sqrt{B}$

J. Bio-Sci. 27: 109-120, 2019

ISSN 1023-8654

http://www.banglajol.info/index.php/JBS/index

DOI: https://doi.org/10.3329/jbs.v27i0.44676

\title{
BIOSYNTHESIS AND ANTIBACTERIAL POTENTIAL OF TECTONA GRANDIS MEDIATED MAGNESIUM OXIDE NANORODS
}

\author{
HA Maishera ${ }^{1}$, FA Kuta ${ }^{1}$, JO Tijani ${ }^{2}$, NU Adabara ${ }^{1}$, AS Adedeji $1^{*}$ and JD Bala ${ }^{1}$ \\ ${ }^{1}$ Department of Microbiology, School of Life Sciences, Federal University of Technology, Minna, Nigeria \\ 2Department of Chemistry, School of Physical Sciences, Federal University of Technology, Minna, Nigeria
}

\begin{abstract}
The high rate of enteric bacterial infection and the increasing drug resistance by pathogenic bacteria have made the search for new antimicrobials inevitable. The aim of the study was to investigate the antibacterial potentials of Tectona grandis magnesium oxide $(\mathrm{MgO})$ nanorods on clinical isolates of Escherichia coli Acj 213, Salmonella Typhi strain T8 and Pseudomonas aeruginosa strain DMI. Magnesium chloride solution ( $50 \mathrm{ml}, 1 \mathrm{M}$ ) was bio reduced to magnesium oxide nanorods using Tectona grandis leaves extract $(10 \mathrm{ml})$. The biosynthesized nanoparticles were characterized using UV-visible spectroscopy (UV-vis), dynamic light scattering (DLS), high resolution transmission electron microscopy (HRTEM), surface area electron diffraction analysis (SAED) and X-ray diffraction techniques (XRD). Similarly, antibacterial effects of the $\mathrm{MgO}$ nanorods were determined using agar well diffusion technique. The biogenic $\mathrm{MgO}$ nanorods colloidal solution was fluffy brown in colour with UV-Vis absorbance peak occurring at $364 \mathrm{~nm}$. The DLS analysis revealed monodispersed $\mathrm{MgO}$ nanorods with $90 \mathrm{~nm}$ hydrodynamic diameter. Furthermore, the XRD analysis showed that the crystalline nature had average size of $30 \mathrm{~nm}$. HRTEM/SAED result revealed a rod shaped polycrystalline $\mathrm{MgO}$ nanorods with $29 \mathrm{~nm}$ average size. The results of the antibacterial test showed that $\mathrm{MgO}$ nanorods had the highest antimicrobial activity $(21.75 \pm 1.79 \mathrm{~mm}, 22.75 \pm 1.70 \mathrm{~mm}$ and $19.75 \pm 1.10 \mathrm{~mm})$ at $500 \mathrm{mg} / \mathrm{ml}$ against E. coli Acj 213, S. Typhi strain T8 and $P$. aeruginosa strain DMI, respectively. The minimum inhibitory concentration for $P$. aeruginosa strain DMl, S. Typhi strain T8 and $E$. coli Acj 213 were $125 \mathrm{mg} / \mathrm{ml}, 62.5$ $\mathrm{mg} / \mathrm{ml}$ and $125 \mathrm{mg} / \mathrm{ml}$, respectively. However, the minimum bacteriocidal concentration was $250 \mathrm{mg} / \mathrm{ml}$, $125 \mathrm{mg} / \mathrm{ml}$ and $250 \mathrm{mg} / \mathrm{ml}$, respectively. The results of this study indicate that the synthesized $\mathrm{MgO}$ nanorods could be a potential antibacterial agent with broad spectrum activities.
\end{abstract}

Key words: Fluffy and hydrodynamic, Magnesium oxide nanorods, Tectona grandis

\section{Introduction}

Metallic oxide nanomaterials, particularly magnesium oxide (MgO) nanorods have emerged as an alternative for the development of new antibacterials to address the global resistance of pathogenic microorganisms. This is due to their unique physical, chemical and antibacterial effect as well as their stability under harsh environmental condition (Sundrarajan et al. 2012). Nanomaterial can be synthesized using physical, chemical and biological methods (Luechinger et al. 2010). Physical and chemical methods are complicated by the formation of toxic by-products. Biological methods of nanosynthesis uses plant extract and microorganisms in an eco-friendly, safe and cost effective process. However, plants seem to be a better candidate due to their aptness and obtainability for the large-scale production of stable nanorods of varied shapes and sizes (Krishnaraj et al. 2010, Ramesh et al. 2014). This is because plants harbour myriad of

\footnotetext{
*Author for correspondence: sabdulameen@futminna.edu.ng
} 
bioactive compounds that participate in the reduction, capping and stabilization of the metallic ions to nanomaterial (Krishnaraj et al. 2010).

Among the several medicinal plants, Tectona grandis (Teak) leaves is known with excellent antioxidant activities, free radical scavenging properties, diuretic and antibacterial property as a function of a huge array of bioactive compounds its contain (Purushotham et al. 2010, Rao et al. 2011). The bioactive component presents in the leaves no doubt it might facilitate the biosynthesis of $\mathrm{MgO}$ nanoparticles. However, the use of $T$. grandis for the synthesis of $\mathrm{MgO}$ nanoparticles has not been reported in spite of its role in traditional folk medicine. The number of difficult-to-treat infectious diseases chiefly, the enteric bacteria associated infection has escalated in recent times due to the emergence and continuous spread of drug resistance mechanisms. Moreover, conventional antibiotics are costly and toxic to human tissue, thereby limiting their use. Thus, the search for alternative antibacterial agent has been intensified. Therefore, the present study focused on the synthesis of MgO nanorods, using Tectona grandis leaves extract alongside its antibacterial potential against selected enteric bacterial pathogens.

\section{Materials and Methods}

\section{Collection of plant materials}

Fresh leaves of Tectona grandis were collected from the forest plantation site of the Federal Ministry of Forestry, Minna, Nigeria. The plant leaves were taken to the Department of Plant Biology, Federal University of Technology, Minna, Nigeria for identification by a taxonomist. The voucher number CA3152 was deposited in the herbarium laboratory of the Department of Plant Biology, Federal University of Technology, Minna, Nigeria.

\section{Preparation of the leaves extract}

The fresh leaves were rinsed three times with distilled water in order to remove dust particles. The leaves were air-dried in the laboratory for 7 days at $28^{\circ} \mathrm{C} \pm 2{ }^{\circ} \mathrm{C}$. The air dried leaves of $T$. grandis were pulverized using an electric blender into a fine powder. The aqueous extraction of the powdered leaves was carried out by weighing $5 \mathrm{~g}$ of the powdered T. grandis leaves into $100 \mathrm{ml}$ of deionized water in a $500 \mathrm{ml}$ beaker. The mixture was agitated for 20 minutes at $60^{\circ} \mathrm{C}$ in the water bath, allowed to cool at room temperature then filtered with Whatman No. 1 (Germany) filter paper (pore size $25 \mu \mathrm{m}$ ). The filtrates were used for qualitative, quantitative phytochemical screening and the synthesis of the MgO nanoparticles (Devasenan et al. 2016).

\section{Phytochemical screening}

Qualitative determination of total phenols, flavonoids and tannins Tectona grandis leaves were screened to determine the presence of phenol, flavonoids and tannins, using standard phytochemical screening procedure (Sofowora 1993).

\section{Total phenolic content (TPC)}

The quantity of phenols in the leaves was determined in accordance with the method described by Vimala et al. (2013). Briefly, $0.01 \mathrm{~g}$ of the powdered leaves was mixed with $10 \mathrm{ml}$ of Methanol and $0.5 \mathrm{ml}$ of Folinciocalteu reagent. The mixture was incubated for 5 minutes at $22^{\circ} \mathrm{C}$, addition of $20 \% \mathrm{Na}_{2} \mathrm{CO}_{3}$ was added and incubated at $22^{\circ} \mathrm{C}$ for 90 minutes. The absorbance of the mixture was read at $765 \mathrm{~nm}$ and the value for the total phenolic content was compared with that of the standard (gallic acid) (Vimala et al. 2013). 


\section{Total flavonoid content (TFC)}

Zeo point five $(0.5 \mathrm{ml})$ of the aqueous crude extract was mixed with $0.5 \mathrm{ml}$ of distilled water and $0.3 \mathrm{ml}$ of $5 \%$ $\mathrm{NaNO}_{2}$. The mixture was incubated for 5 minutes at $25^{\circ} \mathrm{C}$. Zero point three $(0.3 \mathrm{ml})$ of $10 \% \mathrm{AlCl}_{3}$ and $1 \mathrm{M}$ $\mathrm{NaOH}$ was simultaneously added. The absorbance was read at $415 \mathrm{~nm}$. The total flavonoids present were compared with that of the standard (Quercetin) (Vimala et al. 2013).

\section{Total tannin content (TTC)}

Zero point zero two grams $(0.02 \mathrm{~g})$ of the pulverized leaves was weighed into $20 \mathrm{ml}$ of $500 \%$ methanol and covered with paraffin before heating at $80^{\circ} \mathrm{C}$ in water bath for 1 hour. The mixture was then filtered with Whatman No. 1 (Germany) filter paper (pore size $25 \mu \mathrm{m}$ ). $2.5 \mathrm{ml}$ of Follin Denis and $15 \mathrm{mg}$ of $17 \% \mathrm{Na}_{2} \mathrm{CO}_{3}$ were added. The mixture was made up to $100 \mathrm{ml}$ with distilled water and allowed to stand for 20 minutes. The absorbance was read at $760 \mathrm{~nm}$. Tannic acid dilution of $(0-0.5 \mathrm{mg} / \mathrm{ml})$ was used as standard solution. The result was expressed in terms of Tannic acid in $\mathrm{mg} / \mathrm{g}$ of the plant extract (Oloyede 2005).

\section{Biosynthesis of MgO nanorods using T. grandis leaves extract}

Fifty milliliters $(50 \mathrm{ml})$ of the prepared $0.2 \mathrm{M}$ of $\mathrm{MgCl}_{2}$ salt solution was measured into a conical flask and stirred at $200 \mathrm{rpm}$ for 10 minutes with magnetic stirrer. Ten millilitres $(10 \mathrm{ml})$ of the aqueous crude leave extract was added drop-wise and the $\mathrm{pH}$ adjusted to 12 , using $0.2 \mathrm{M}$ of $\mathrm{NaOH}$, while the stirring continued for 15 minutes. A change of colour from dark brown to fluffy brown colloidal solutions was observed. The resulting colloidal solution was centrifuged at $4000 \mathrm{rpm}$ for 20 minutes and the supernatant was discarded. The residues were washed thrice with distilled water then dried in an oven at $80^{\circ} \mathrm{C}$ for 3 hours. The air-dried residue was calcined at $200^{\circ} \mathrm{C}$ for 5 hours (Nadanathangam et al. 2006).

\section{Characterization of the synthesized MgO nanoparticles}

The synthesis of the MgO nanoparticles was evaluated using UV-Vis spectrophotometer to determine the absorption spectra of synthesized $\mathrm{MgO}$ nanoparticles. The particle size distribution and polydispersity index of the sample were obtained by dynamic light scattering technique using Malvern®Zetasizer Nano ZS (Malvern Panalytical, U.K). The crystalline structure of the nanorods was also analysed by an X-ray diffractometer (XRD) (Malvern Panalytical, U.K). High Resolution Transmission electron microscope (HRTEM) (Carl Zeiss AG, Germany) was used to investigate the microstructure of the MgO nanorods and the elemental composition of the synthesized $\mathrm{MgO}$ nanorods was also determined by energy dispersive $\mathrm{x}$-ray spectroscopy (EDS). The crystallite size was calculated using Scherrer equation. Debye Scherer ${ }^{\wedge^{\prime}} \mathrm{s}$ formula $=0.9 \mathrm{AB} \cos \theta \mathrm{B}$

Where, $D$ - Crystallite size, $\lambda$ - X-ray wavelength (1.5406), $\theta B$ - Angle of the Bragg diffraction peak of the most intense peak (in radians), $B$-Full width at half maximum of the most intense peak.

\section{Antibacterial activity of the synthesized $\mathrm{MgO}$ nanorods}

MgO nanorods (at $200 \mathrm{mg} / \mathrm{ml}, 300 \mathrm{mg} / \mathrm{ml}, 400 \mathrm{mg} / \mathrm{ml}$ and $500 \mathrm{mg} / \mathrm{ml}$ ) were screened for their antibacterial effect in comparison with leaves extract, $\mathrm{MgCl}_{2}$ salt solution and $30 \mu \mathrm{g} / \mathrm{ml}$ standard antibiotics (Ampicloxbeecham). This was done in vitro by agar well diffusion method (Padmavathy and Vijavaraghavan 2012). Twenty milliliter $(20 \mathrm{ml})$ of sterilized nutrient agar was dispensed into each of 12 sterile petri dishes. The agar was allowed to set, inoculated (with a loop full standardized inocula), and in each of the plate, $6 \mathrm{~mm}$ wells were bored on each of the plate using a sterile cork borer (Devi et al. 2012). The wells were filled with $160 \mu$ l $\mathrm{MgO}$ nanoparticles. This was allowed to diffuse at room temperature for two hours and incubated at $37^{\circ} \mathrm{C}$ for 
18 hours. The diameters of each inhibition zone formed around the wells were measured (Padmavathy and Vijavaraghavan 2012). All tests were conducted in quadruplicate.

\section{Determination of minimum inhibitory concentration and minimum bactericidal concentration}

Minimum inhibitory concentration (MIC) and minimum bacteriocidal concentration (MBC) of the $\mathrm{MgO}$ nanorods were determined as described by (Fakruddin 2006). Serial dilution of the synthesized MgO nanorods was done using $2 \mathrm{ml}$ of nutrient broth in six (6) test tubes to obtain varied concentrations $(500,250$, $125,62.5,31.25$ and $15.125 \mu \mathrm{g} / \mathrm{ml}$ ). The tubes were inoculated with $0.2 \mathrm{ml}$ of standardized inocula of the bacterial isolates and incubated over night at $37^{\circ} \mathrm{C}$. The tubes containing broth and $\mathrm{MgO}$ nanorods without inocula served as positive control, while tubes containing broth and inocula served as negative control. Thereafter, the tubes were examined for visible growth. Culture tube with lowest concentration of the MgO nanorods which did not show any visible sign of growth was taken as the MIC value. Thereafter, culture tubes that showed no evidence of growth were inoculated on freshly prepared nutrient agar plates. The plates were incubated overnight at $37^{\circ} \mathrm{C}$ while the lowest concentration at which there was no growth was taken as the MBC value (CLSI 2008).

\section{Results and Discussion}

\section{Phytochemical analyses}

The result for the qualitative phytochemical analysis of the $T$. grandis aqueous leaves extract revealed the presence of phenols, tannins and flavonoids (Table 1). Quantitatively, the leaves extract contained 7.99 $\mathrm{mg} / \mathrm{ml}$ of total phenols, $4.61 \mathrm{mg} / \mathrm{ml}$ of total tannins and $0.61 \mathrm{mg} / \mathrm{ml}$ of total flavonoids (Table 1).

Table 1. Qualitative and quantitative phytochemical screening of $T$. grandis leaves extract

\begin{tabular}{lcc}
\hline Phytochemicals & Qualitative & $\begin{array}{c}\text { Quantitative } \\
(\mathrm{mg} / \mathrm{ml})\end{array}$ \\
\hline Total Phenols & ++ & 7.99 \\
Tannins & ++ & 4.61 \\
Flavonoids & + & 0.61 \\
\hline
\end{tabular}

$++=$ Moderately present, $+=$ Present 


\section{Biosynthesis of MgO nanorods}

The reaction of $0.2 \mathrm{M} \mathrm{MgCl}_{2}$ with aqueous leaves extract at a pH of 12 (the initial $\mathrm{pH}$ of mixture was 5.4) demonstrated a change in colour of the reactant from dark brown to a fluffy brown colloidal solution (Fig. 1 \& 2). The colour change signals the successful reduction of the $\mathrm{MgCl}_{2}$ ions to $\mathrm{MgO}$ nanoparticles.

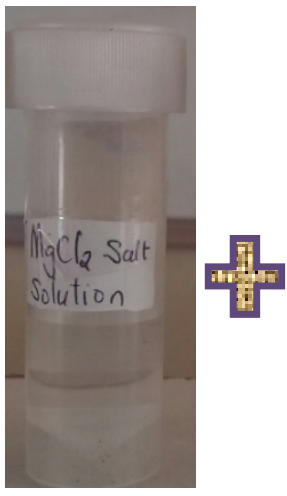

a

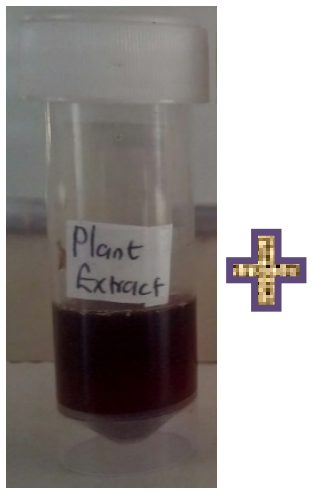

b

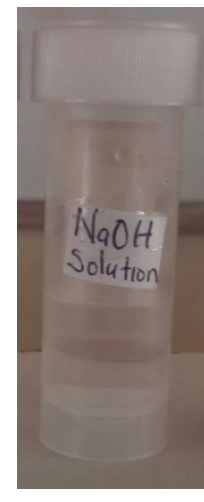

C

c

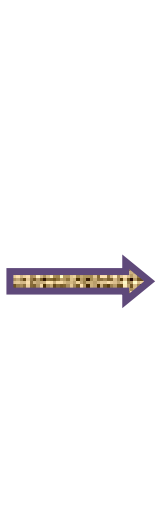

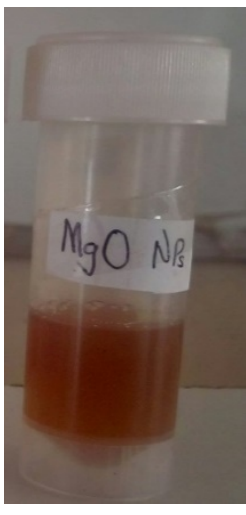

d

Fig. 1. Optical photograph of $\mathrm{MgCl}_{2}$ solution (a), T. grandis aqueous extract (b), $\mathrm{NaOH}$ (c) and $\mathrm{MgO}$. nanorods suspension (d).

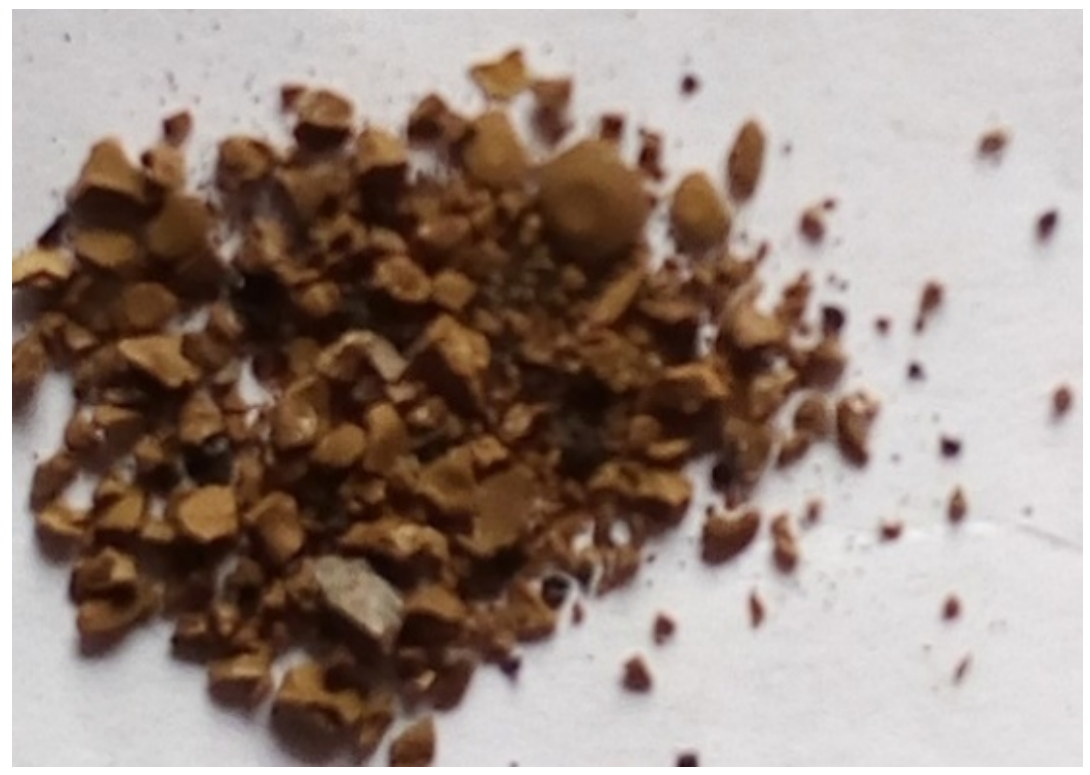

Fig. 2. $\mathrm{MgO}$ nanorods after calcination at $200^{\circ} \mathrm{C}$. 


\section{UV-Vis spectroscopy}

The UV-Vis spectroscopy revealed a strong and broad surface plasmon resonance (SPR) peak at $364 \mathrm{~nm}$ with an absorbance of 2.25 obtained for magnesium oxide nanoparticles (Fig. 3).

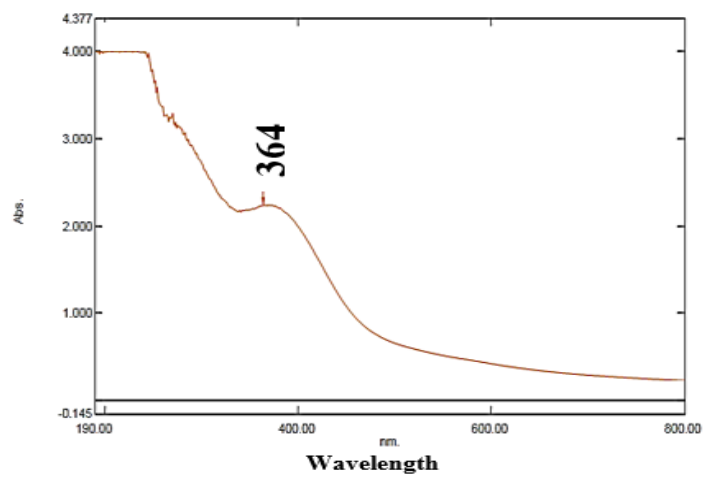

Fig. 3. UV-Vis spectrum of the MgO nanoparticles

\section{Size analysis of $\mathrm{MgO}$ nanoparticles}

The size distribution of $\mathrm{MgO}$ was measured using dynamic light scattering principle. The histogram revealed the particle size distributions of $\mathrm{MgO}$ nanorods dispersed in water (Fig. 4). The hydrodynamic diameter was found to be $90 \mathrm{~nm}$. The polydispersity index (Pdl) was 0.603 .

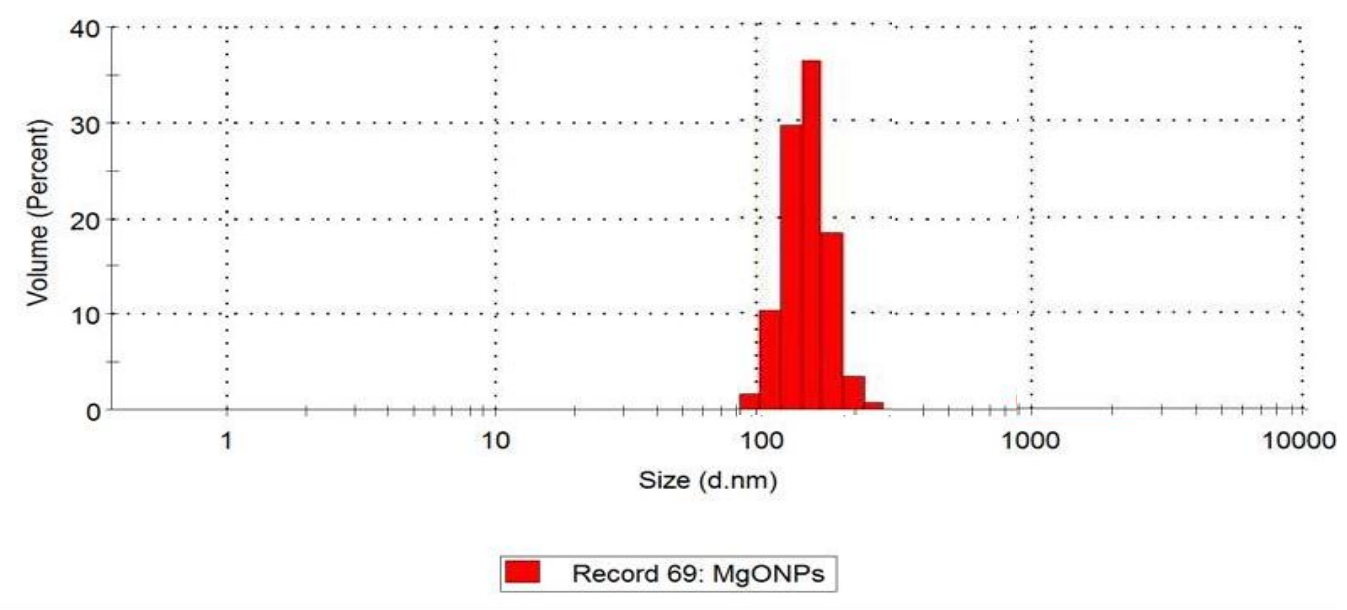

Fig. 4. Average particle size of the MgO nanorods. 


\section{$X$-ray diffraction}

The XRD pattern of MgO nanoparticle as revealed by JCPDS card no. 00-007-0239, showed broad peaks with high intensities of $\mathrm{MgO}$ crystallites. The peak $\left(2^{\theta}=18.08^{\circ}, 31.57^{0}, 37.67^{0}, 50.16^{\circ}, 58.56^{\circ}, 61.72^{\circ}\right.$ and $71.67^{\circ}$ ) corresponds to $001,100,101,102,110,111$ and $103 \mathrm{MgO}$ crystallites crystal plane (Fig. 5). The crystallite size was calculated using Scherrer equation to be around $30 \mathrm{~nm}$.

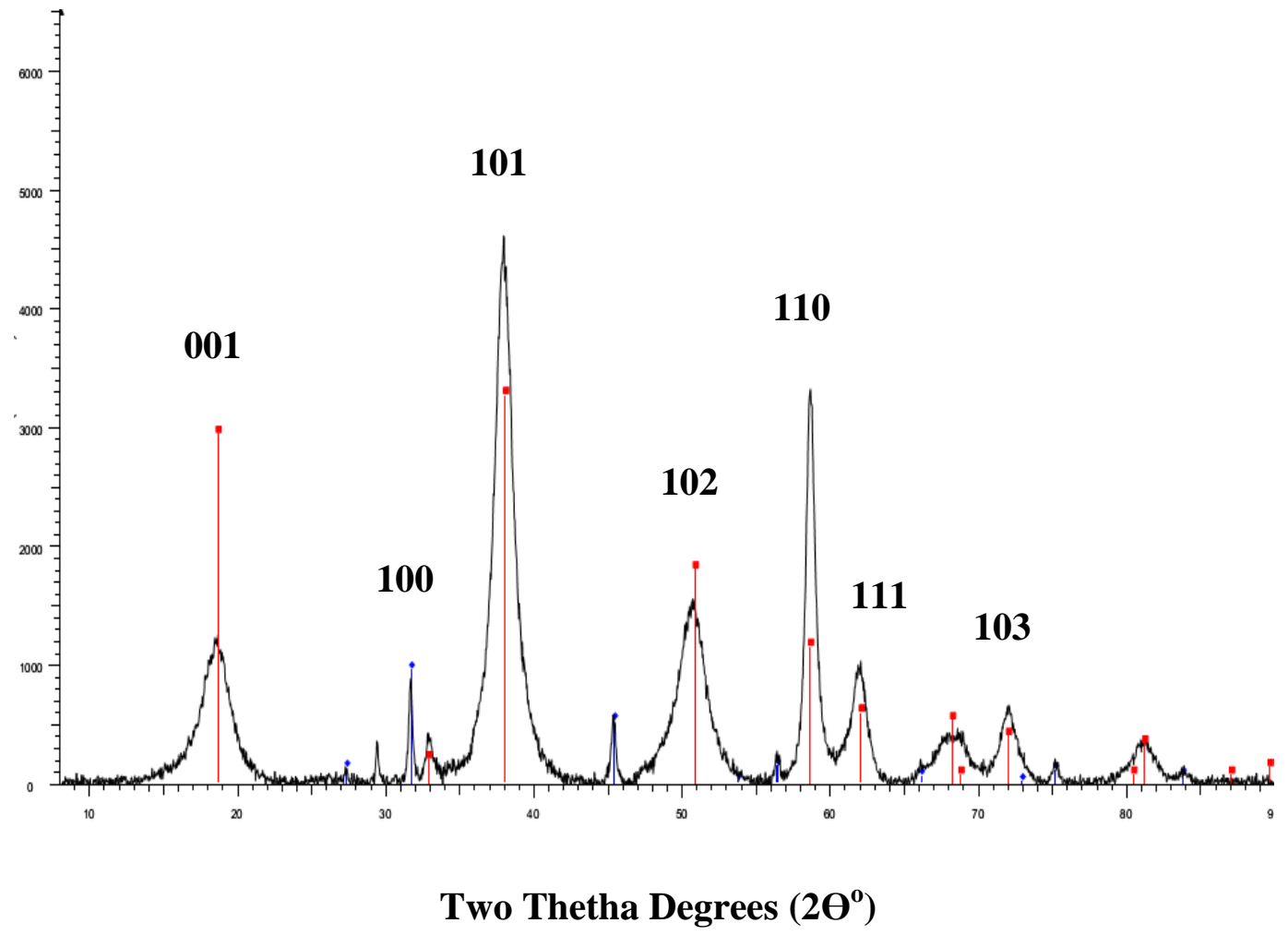

Fig. 5. XRD pattern for the MgO nanorods.

HRTEM/SAED analysis of the synthesized MgO

The HRTEM micrographs revealed a rod shape nanomaterial with average size of $29 \mathrm{~nm}$ (Fig. 6). The SAED image (Plate IID) showed distinct ring patterns (a-d) which correspond to the XRD planes. 


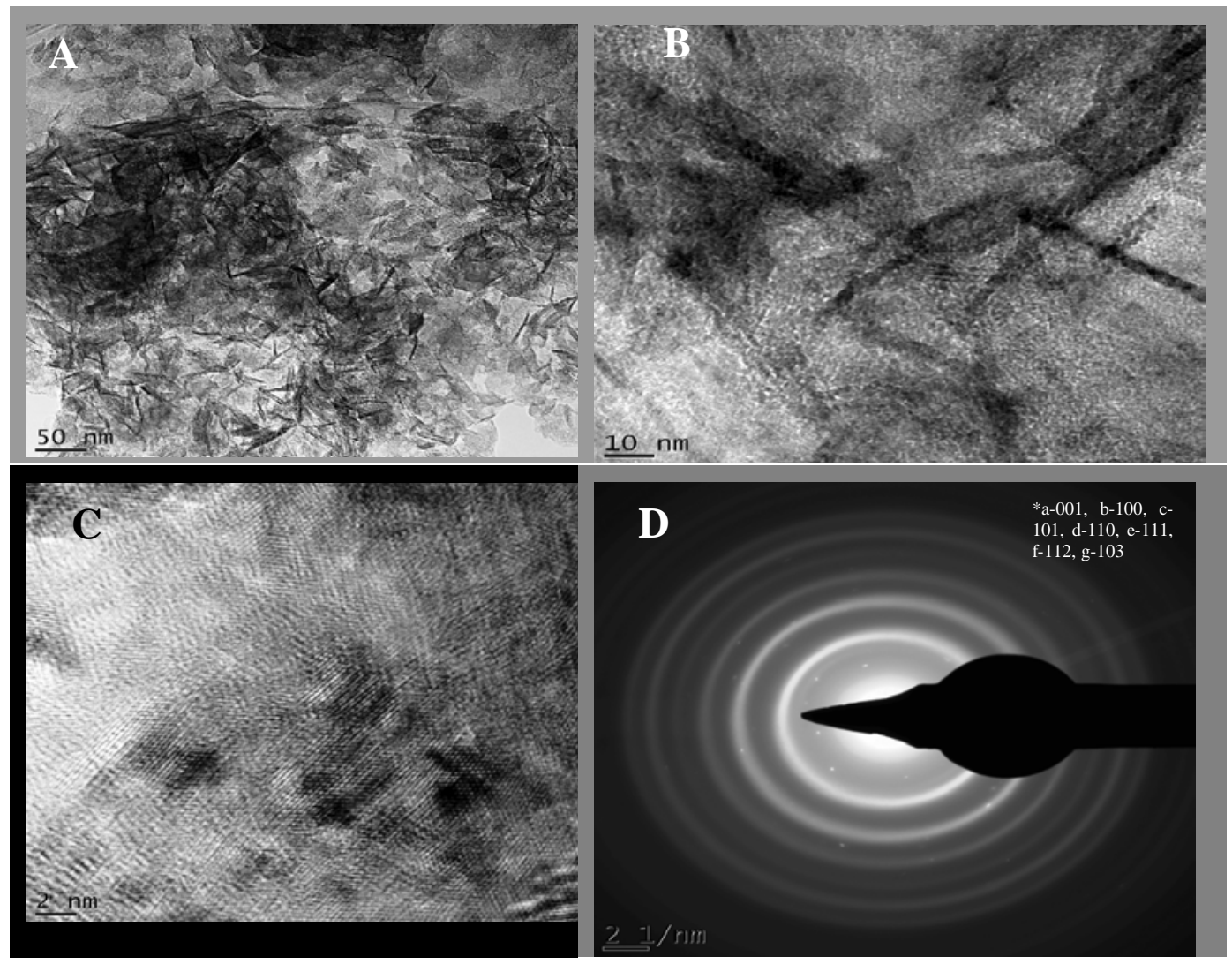

Fig. 6 (A-C). HRTEM images of the synthesized MgO nanorods, D) selected area electron diffraction pattern of $\mathrm{MgO}$ nanorods.

\section{Elemental composition of $\mathrm{MgO}$ nanorods}

The elemental composition of the nanomaterial was determined using energy dispersive X-ray spectroscopy. The result confirms the successful biosynthesis of $\mathrm{MgO}$ nanorods by appearance of $\mathrm{Mg}$ and $\mathrm{O}$ peaks (Fig. 7). However, the appearance of other peaks such as chloride may be from the unreacted $\mathrm{MgCl}_{2}$ used as the precursor. The copper originated from the copper grid and/or plant extract used for the reduction of magnesium salt while carbon is from the carbon coating used during the process of the TEM analysis. 


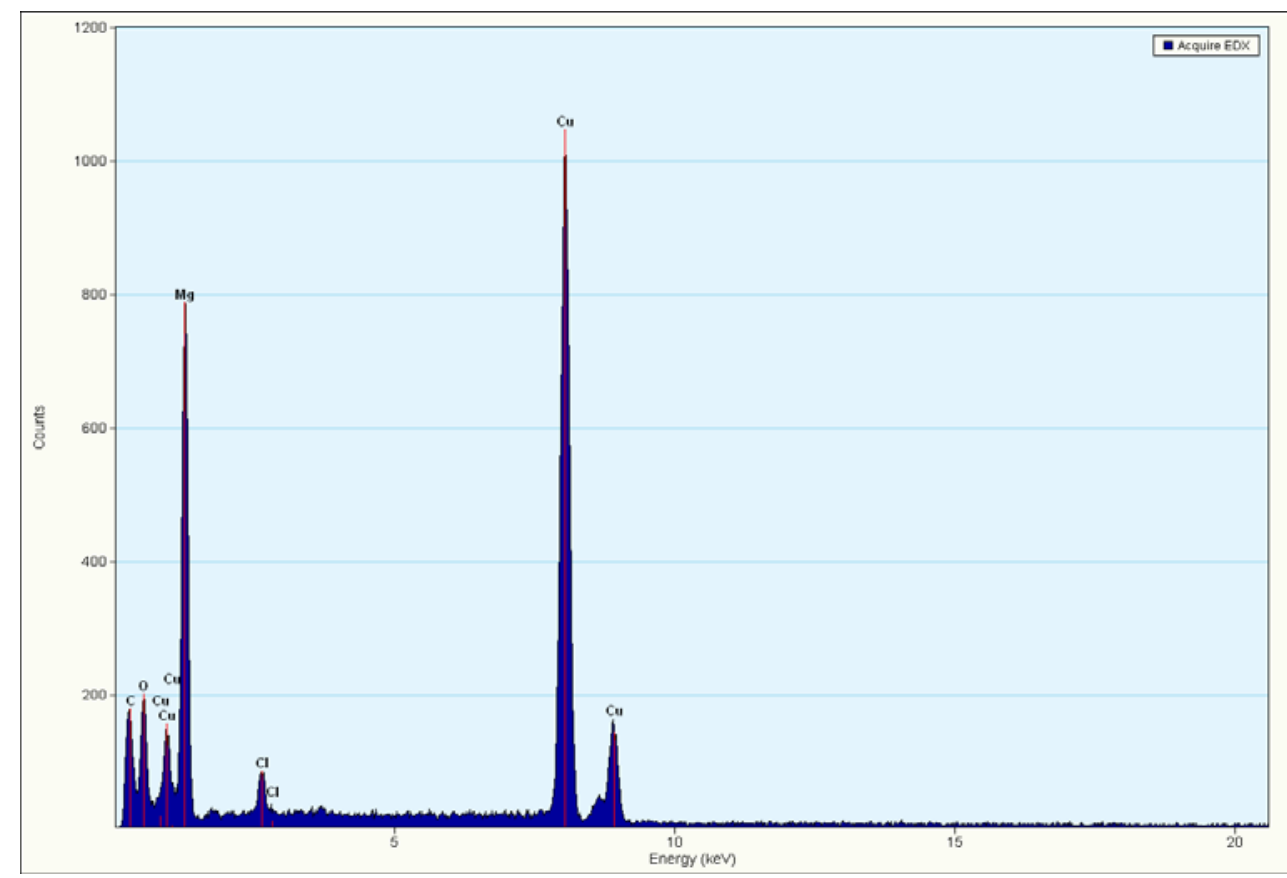

Fig. 7. Energy dispersive X-ray spectroscopy profile of the MgO nanorods.

\section{Antibacterial susceptibility test of the three pathogens}

The antibacterial activity of the $\mathrm{MgO}$ nanorods at various concentrations $(200 \mathrm{mg} / \mathrm{ml}, 300 \mathrm{mg} / \mathrm{ml}, 400 \mathrm{mg} / \mathrm{ml}$ and $500 \mathrm{mg} / \mathrm{ml}$ ) showed remarkable activities against $P$. aeruginosa strain DMI, S. typhi strain T8 and E. coli Acj 213 (Table 2) with zones of inhibition ranging from 22.75 to 14.25 .

Table 2. Zones of inhibition (Mm) produced by MgO Nanorods against the bacterial isolates

\begin{tabular}{cccc}
\hline MgONPs( mg/ml) & P. aeruginosa & S. typhi & E. coli \\
\hline 500 & $19.75^{\mathrm{d}} \pm 1.10$ & $22.75^{\mathrm{f}} \pm 1.70$ & $21.75^{\mathrm{e}} \pm 1.79$ \\
400 & $17.75^{\mathrm{c}} \pm 0.25$ & $19.50^{\mathrm{d}} \pm 1.93$ & $19.25^{\mathrm{d}} \pm 0.75$ \\
300 & $17.5^{\mathrm{c}} \pm 0.28$ & $16.75^{\mathrm{cd}} \pm 1.10$ & $17.25^{\mathrm{c}} \pm 1.10$ \\
200 & $15.75^{\mathrm{c}} \pm 0.75$ & $15.00^{\mathrm{c}} \pm 1.08$ & $14.25^{\mathrm{c}} \pm 0.75$ \\
$\mathrm{MgCl}_{2}$ & $6.00^{\mathrm{b}} \pm 0.31$ & $9.30^{\mathrm{b}} \pm 0.00$ & $8.00^{\mathrm{b}} \pm 0.00$ \\
Plant extract & $0.00^{\mathrm{a}} \pm 0.00$ & $5.00^{\mathrm{a}} \pm 0.00$ & $6.50^{\mathrm{a}} \pm 0.00$ \\
Ampiclox & $29.00^{\mathrm{e}} \pm 0.00$ & $24.00^{\mathrm{e}} \pm 0.00$ & $27.00^{\mathrm{e}} \pm 0.00$
\end{tabular}

Values are mean \pm SEM of 3 determinations. Values along the same column with different superscripts are significantly different $(p<0.05)$. 


\section{Minimum inhibitory concentration and minimum bactericidal concentration of MgO nanorods}

The MIC of MgO nanorods against $P$. aeruginosa strain DMI, S. typhi strain T8 and E. coli Acj 213 were 125 $\mathrm{mg} / \mathrm{ml}, 62.5 \mathrm{mg} / \mathrm{ml}$ and $125 \mathrm{mg} / \mathrm{ml}$, repectively while that of the MBC were $250 \mathrm{mg} / \mathrm{ml}, 125 \mathrm{mg} / \mathrm{ml}$ and 250 $\mathrm{mg} / \mathrm{ml}$, respectively (Table 3). The absolute values for MIC and MBC of the $\mathrm{MgO}$ nanorods were $250 \mathrm{mg} / \mathrm{ml}$ and $500 \mathrm{mg} / \mathrm{ml}$, respectively.

Table 3. MIC and MBC of MgO nanorod concentrations against the isolates

\begin{tabular}{cccc}
\hline Analysis & P. aeruginosa & S. typhi & E. coli \\
\hline $\operatorname{MIC}(\mathrm{mg} / \mathrm{ml})$ & 125 & 62.5 & 125 \\
$\mathrm{MBC}(\mathrm{mg} / \mathrm{ml})$ & 250 & 125 & 250 \\
\hline
\end{tabular}

The absolute MIC and MBC values were 62.5 and $125 \mathrm{mg} / \mathrm{ml}$

\section{Discussion}

Phytochemical screening of the plant extract revealed the presence of phenols, tannins and flavonoids in the powdered leaves of $T$. grandis (Table 1). Quantitatively, $T$. grandis phenols and tannins content $(7.99 \mathrm{mg} / \mathrm{ml}$ and $4.608 \mathrm{mg} / \mathrm{ml}$ ) were higher in comparison to the standard $(0.500 \mathrm{mg} / \mathrm{ml})$. This result is in agreement with the findings of Kushwah et al. (2013) that reported alkaloids, phenols and flavonoids in aqueous extract of $T$. grandis and found phenol to be higher than the flavonoids. The low tannin concentration $(0.605 \mathrm{mg} / \mathrm{ml})$ obtained was in agreement to Shyamij et al. (2016). Reaction mixture colour changes and UV-Vis spectroscopy are gold standards for the monitoring of reduction of metallic ion to nanoparticle during biosynthesis. The absorption peak at $364 \mathrm{~nm}$ is an indication of the reduction of $\mathrm{MgCl}_{2}$ by the $T$. grandis bioactive constituents (Fig. 2). This result is in line with Gaurav et al. (2017) who observed colour changes from green to brownish colloidal suspension for a mixture of $\mathrm{Mg}\left(\mathrm{NO}_{3}\right)_{2}$ and $\mathrm{S}$. chirayaita crude leaves aqueous extract.

The hydrodynamic diameter and poly dispersity index (PDI) of the biosynthesized MgONps as measured by particle size analyzer (PSA) was $90 \mathrm{~nm}$ and 0.603 , respectively. PDI greater than 0.5 indicates aggregation of particles (Nanocomposix 2015). Thus, MgONps from this study are monodispersed as evidenced in the HRTEM micrographs (Plate II). Yuvakkumar et al. (2014) observed that PSA measures mean particles size and its distribution but not the actual sizes. More so, the presence of ions and ligand in the colloidal suspension are known to alter colloidal particle size. Therefore, the observed variation in the determined size by HRTEM and XRD is not uncommon. Previous study (Yuvakkumar et al. 2014) reported 80-300 nm MgO nanoparticle, which is comparable with ours.

The XRD analysis carried out was to determine the crystalline nature of $\mathrm{MgO}$ nanorods. According to the JCPDS file no. (00-007-0239), the major peaks (at $2^{\theta}=18.08^{\circ}, 31.57^{\circ}, 37.67^{\circ}, 50.16^{\circ}, 58.56^{\circ}, 61.72^{\circ}$ and 71.670 ) in the XRD pattern correspond to the following crystal planes (001), (100), (101), (102), (110), (111) and (103) illustrating the crystalline face of MgONPs. Using XRD data, the crystallite size was approximately $30 \mathrm{~nm}$. The result is in agreement with the findings of Devi et al. (2012) who reported $30 \pm 10 \mathrm{~nm}$ biosynthesized MgONP.

Plate II (A-D) illustrates the HRTEM images of pure MgO nanorods with an average size of $\sim 29 \mathrm{~nm}$. Presence of lattice fringes (parallel line observed in the TEM images) shown in plate II (C) agrees with the 
report from XRD and highlights the crystalline nature of the biogenic MgONPs. SAED pattern (Plate IID) revealed seven discernible diffraction rings (a-g) indexed as (001), (100), (101), (102), (110), (111) and (103) planes which correspond with the observation in XRD pattern earlier reported. This further justifies the crystalinity of the MgONPs nanorods. This result is similar to that obtained by Devaraja et al. (2015) and agrees with the results obtained from the EDX and SAED analysis. The elemental mineral distributions mainly consist of magnesium and oxygen in different proportion. This result agrees with the work of Devaraja et al. (2015) where only $\mathrm{Mg}$ and $\mathrm{O}$ were observed in the EDX profile. However, there are some chloride peaks present which may be from the unreacted $\mathrm{MgCl}_{2}$ used as the precursor. The copper originated from the copper grid and/or plant extract used for the reduction of magnesium salt while carbon is from the carbon coating used during the process of the TEM analysis.

The reported broad spectrum antibacterial activity of nanoparticles could be attributed to a combined effect between their physical properties and the released free metallic ions. The test isolates showed susceptibility to the MgNPs with zones of inhibition as high as $22.75 \pm 1.70$ at $500 \mathrm{mg} / \mathrm{mL}$ against S. Typhi, while the least was $14.25 \pm 0.75$ at $200 \mathrm{mg} / \mathrm{ml}$ against $E$. coli. The absolute MIC and MBC values for the test isolates were 62.5 and $125 \mathrm{mg} / \mathrm{ml}$. The observed inhibition zones were dose dependent except for S. Typhi were all significantly lower when compared to inhibition zones produced by the standard drug. Also, the $\mathrm{MgCl}_{2}$ salt used as precursor in the nanorods synthesis as well as the aqeous leave extract of Tectona grandis showed lower antibacterial activities against the selected organisms when compared to the synthesized nanrods. This finding is similar to previous studies (Sawai 2003, Jin and He 2011) that MgO nanorods have concentration dependent antibacterial activity. Also, the results for MIC of $E$. coli and P. aeruginosa are a bit different from the findings of Karthikeyan et al. (2012) where the MgONPs MICs were found to be 500 and $1000 \mu \mathrm{g} / \mathrm{ml}$, respectively.

\section{Acknowledgments}

We sincerely acknowledge Mr Adelere Ishaka and Bashir Lawal for the technical assistance. Also, the management and staff of the Center for Vaccine and Drug development "Step B", Federal University of Technology Minna, Niger State, Nigeria for their contribution in providing the bench space and the equipment used for the study.

\section{References}

Clinical and Laboratory Standards Institute (2008). Performance standards for antimicrobial disk diffusion susceptibility tests for bacteria isolated from animals; approved standard, $3^{\text {rd }}$ Edition, M31-A3 28(8): 1-99.

Devaraja PB, Avadhani DN, Nagabhushana H, Prashanthad SC, Sharmae SC, Nagabhushana BM, Nagaswarupa HP and Daruka PB (2015). Luminsescence Properties of MgO: Fe ${ }^{3+}$ Nanopowders for WLEDs under NUV Excitation Prepared Via Propellant Combustion Route. Journal of Radiation Research and Applied Sciences, 8: 362-373.

Devasenan S, Beevi NH and Jayanthi SS (2016). Synthesis and characterization of copper nanoparticles using leaf extract of Andrographis paniculata and their antimicrobial activities. International Journal of Chem Tech Research, 9(4): 725-730.

Devi MS, Rajarajan M, Susai R, Robert KZ and Brindha G (2012). Synthesis and characterization of magnesium oxide nanoparticles. Nanotechnology, 50: 10618-10620.

Fakruddin M (2006). Assay of antibacterial activities of antibiotics using micro-dilution broth procedure. Dept. of Microbiology, University of Dhaka, pp. 67-86.

Gaurav S, Rajgovind S and Nakuleshwar DJ (2006). Phyto-assisted synthesis of magnesium oxide nanoparticles with Swertia chirayaita. Journal of Taibah University for Science, 11: 471-477. 
Jin T and He YP (2011). Antibacterial activities of magnesium oxide (MgO) nanoparticles against foodborne pathogens. Journal of Nanoparticles Research, 13: 6877-6885.

Karthikeyan K, Mariappan P and Kadarkaraithangam J (2012). Antibacterial activity of MgO nanoparticles based on lipid peroxidation by oxygen vacancy. Journal of Nanoparticle Research, 12: 1063-1066.

Krishnaraj C, Jagan EG, Rajasekar S, Selvakumar P, Kalaichelvan PT and Mohan N (2010). Synthesis of silver nanoparticles using Acalypha indica leaf extracts and its antibacterial activity against water borne pathogens. Colloids Surface B Biointerfaces, 76: 50-56.

Nadanathangam V, Sampath K, Kathe AA, Varadarajan PV and Virendra P (2006). Functional finishing of cotton fabrics using zinc oxide soluble starch nanocomposites. Nanotechnology, 17: 5087-509.

Nanocomposix (2015). Nano Composix's Guide to Dynamic Light Scattering Measurement and Analysis, 1(4).

Oloyede Ol (2005). Chemical profile of unripe pulp of Carica papaya. Pakistan Journal of Nutrition, 4: 379-381.

Padmavathy $\mathrm{N}$ and Vijayaraghavan $\mathrm{R}$ (2008). Enhanced bioactivity of ZnO nanoparticles and antimicrobial study. Science and Technology of Advanced Materials, 9(3): 035004.

Purushotham G, Arun P, Jayarani JJ, Vasnthakumari R, Sankar L and Raviprakash BR (2010). Synergistic in vitro antibacterial activity of Tectona grandis leaves with tetracycline. International Journal of PharmTech Research, 2: 519-523.

Ramesh AV, Pavankumar Y, Lavakusa B and Basavaiah K (2017). A facile green synthesis of ZnO nanorods using leaf extract of Ficus hispida L. International Journal of Engineering Applied Sciences and Technology, 2(4): 256-260.

Rao KNV, Aradhana R, Banjii D, Chaitanya RSN and Anil Kumar AV (2011). In vitro antioxidant and free radical scavenging activity of various extracts of Tectona grandis Linn leaves. Journal of Pharmacy Research, 4: 440-442.

Sawai J (2003). Quantitative evaluation of antibacterial activities of metallic oxide powders ( $\mathrm{ZnO}, \mathrm{MgO}$ and $\mathrm{CaO}$ ) by an indirect conduct metric assay. Journal of Microbiological Methods, 54: 177-182.

Shyamji S, Nidhi M, Harshita S and Sardul S (2016). Evaluation of antibacterial potential of different extracts of Tectona grandis. World Journal of Pharmacy and Pharmaceutical Science, 5: 1272-1281.

Sundrarajan M, Suresh $\mathrm{J}$ and Rajivgandhi R (2012). A comparative study on antibacterial properties of MgO nanoparticles prepared under different calcination temperature. Digest Journal of Nanomaterial and Biostructures, 7(3): 983-989.

Vimala A, Thamizharasi T, Sathish SS, Palani R and Vijayakanth P (2013). Phytochemical studies on selective medicinal plants. Int. J. Research in Engineering and Biosciences, 1: 57-62.

Yuvakkumar R, Suresh J, Joseph NA, Sundrarajan M and Hong SI (2014). A comparative study on antibacterial and wash durability behaviour of $\mathrm{ZnO}$ and $\mathrm{CuO}$ nanoparticles treated cotton fabric using sodium alginate as cross linker. Applied Mechanics and Materials, 508: 44-47.

(Manuscript received on August 18, 2018 and revised on December 22, 2018) 